\title{
Evaluation of Insecticides against Tobacco Mealy Bug, Phenacoccus solenopsis Tinsley and its Parasitoid, Aenasius bambawalei Hayat under Laboratory Conditions
}

\author{
N. A. Bhatt* and Jalpa P. Lodaya \\ AINP on Tobacco, Anand Agricultural University, Anand, India \\ Main Vegetable Research Station, Anand Agricultural University, Anand, India \\ *Corresponding author
}

A B S T R A C T

\begin{tabular}{|l|}
\hline Ke y w or d s \\
Phenacoccus \\
solenopsis Tinsley, \\
Insecticide, \\
Aenasius \\
bambawalei Hayat
\end{tabular}

\section{Introduction}

In India, principle states producing tobacco are Andhra Pradesh, Karnataka, Gujarat, Bihar, West Bengal and Tamil Nadu. Among these states bidi tobacco (Nicotiana tabacum L.) and chewing tobacco (Nicotiana rustica L.) are largely cultivated in middle Gujarat agro climatic zone. Tobacco being a long duration crop, it passes through various biotic stresses like insect pests causing quantitative and qualitative damage. In recent past, tobacco has been found to attacked by mealy bug,
Phenacoccus solenopsis Tinsley (Hemiptera: Pseudococcidae); a major species occurring on cotton in middle Gujarat (Jhala et al., 2008). Bhatt et al., (2009) reported, presence of hymenopterans parasitoid, Aenasius bambawalei Hayat (Chaeidodea: Aphelinidae) on P. solenopsis.

The parasitism was ranged from $6.25-29.94 \%$ (Average 13.8\%). With view to above, present experiment was proposed with following objective includes, to evaluate the toxicity of recommended insecticides against parasitoid 
of mealy bug. And also to evaluate the toxicity of recommended insecticides against mealy bug.

\section{Materials and Methods}

The experiment was carried out for three years, 2014-15, 2015-16, 2016-17 at entomology laboratory, Bidi Tobacco Research Station, AAU, Anand in completely randomized design with six treatment including five insecticides and water spray as control (Table 1) with three repetitions.

\section{Methodology followed for laboratory experiment}

\section{For mealybug}

Tobacco was grown as per recommended agronomical practice. When sufficient population of mealybug built up in the crop, different treatments were imposed to the plants in the morning.

Three leaves from each treatment were plucked and brought into the laboratory after 2 hrs. of insecticidal application. Bases of the leaves were wrapped with moisten cotton swab to maintain turgidity and kept in the glass chimney for further observations. Each leaf was considered as one repetition and mortality of mealy bug was recorded.

\section{For parasitoid}

To evaluate toxicity of insecticides against parasitoid (A. bambawalei) of mealybugs, mummified mealybugs with presence of parasitoids were identified and collected from the treated plots, these mummified mealybugs were brought to the laboratory and kept in the Petri dish for further observations. Observations on number of parasitoids, $A$. bambawalei emerged out were recorded daily up to 10 days.

\section{Results and Discussion}

Evaluation of the insecticides against mealy bug and its natural enemy was carried out in laboratory conditions. The data on mortality of mealy bug $P$. solenopsis and its parasitoid in Table 2 revealed that all the tested insecticides were highly toxic to mealy bug, $P$. solenopsis and its parasitoid, A. bambawalei. Under laboratory conditions cent percent mortality was registered hence the statistical analysis using ANOVA was not performed but mean value was worked out and placed in the Table 2. In contrast to the insecticidal treatment, a control (water spray) was found safe to the parasitoid, A. bambawalei under controlled conditions. All most all the mealy bug and its parasitoids were found live in a treatment without insecticidal application (Table 2).

Table.1 Treatment details

\begin{tabular}{|l|c|c|c|}
\hline Treatments & g a. i./ha & $\begin{array}{c}\text { Concentration } \\
(\%)\end{array}$ & $\begin{array}{c}\text { Formulation } \\
(\mathbf{m l} \text { or g / 10 / water) }\end{array}$ \\
\hline Triazophos 40 EC & 600 & 0.06 & 15 \\
\hline Azadirachtin 1 EC & 90 & 0.003 & 30 \\
\hline Imidacloprid 17.8 SL & 20 & 0.004 & 2.2 \\
\hline Thiamethoxam 25 WG & 25 & 0.005 & 2.0 \\
\hline Buprofezin 25 SC & 250 & 0.05 & - \\
\hline Water spray & - & - & - \\
\hline
\end{tabular}


Table.2 Evaluation of insecticides for their toxicity on mealybug and its parasitoid (Pooled of 2014-15, 2015-16 and 2016-17)

\section{Evaluation of insecticides for their toxicity against mealybug}

\begin{tabular}{|c|c|c|c|c|c|c|c|c|}
\hline \multirow[t]{2}{*}{ Treatments } & \multicolumn{4}{|c|}{$\begin{array}{l}\text { No. of live mealybug } \\
\text { (Before spray) }\end{array}$} & \multicolumn{4}{|c|}{$\begin{array}{l}\text { No. of live mealybug } \\
\text { (After spray) }\end{array}$} \\
\hline & 2014-15 & 2015-16 & 2016-17 & Av & 2014-15 & 2015-16 & 2016-17 & Av \\
\hline Triazophos 40 EC & 35 & 10 & 30 & 25 & 0 & 0 & 0 & 0 \\
\hline Azadirachtin 1 EC & 35 & 10 & 30 & 25 & 0 & 0 & 0 & 0 \\
\hline Imidacloprid 17.8 SL & 35 & 10 & 30 & 25 & 0 & 0 & 0 & 0 \\
\hline Buprofezin 25 SC & 35 & 10 & 30 & 25 & 0 & 0 & 0 & 0 \\
\hline Water spray & 35 & 10 & 30 & 25 & 35 & 10 & 28 & 24 \\
\hline \multicolumn{9}{|c|}{ Evaluation of insecticides for their toxicity against parasitoid } \\
\hline Treatments & \multicolumn{4}{|c|}{ Parasitized mealybug } & \multicolumn{4}{|c|}{$\begin{array}{c}\text { Live parasitoids emerged from mummified } \\
\text { mealybug } 10 \text { DAT }\end{array}$} \\
\hline Imidacloprid 17.8 SL & 10 & 10 & 20 & 13 & 0 & 0 & 0 & 0 \\
\hline Thiamethoxam 25 WG & 10 & 10 & 20 & 13 & 0 & 0 & 0 & 0 \\
\hline Buprofezin 25 SC & 10 & 10 & 20 & 13 & 0 & 0 & 0 & 0 \\
\hline Water spray & 10 & 10 & 20 & 13 & 9 & 9 & 17 & 9 \\
\hline
\end{tabular}


The data presented in Table 2 indicated that, insecticides viz., triazophos $40 \mathrm{EC}$, azadirachtin $1 \mathrm{EC}$, imidacloprid $17.8 \mathrm{SL}$, thiamethoxam $25 \mathrm{WG}$ and buprofezin $25 \mathrm{SC}$ tested against mealybug and its parasitoids under laboratory conditions were found highly toxic to both.

The findings of Sangle et al., (2011), Nalini and Manickavasagam (2011), Suroshe et al., (2014), Minu and Pala ram (2014), Badshah et al., (2015), Nagrare et al., (2016), Badshah et al., (2017), are in conformity with our results.

In conclusion, the evaluated insecticides viz., triazophos 40 EC @ 0.06\%, imidacloprid 17.8 SL@0.004\%, thiamethoxam 25 WG @ $0.005 \%$, buprofezin 25 SC @ $0.005 \%$ and azadirachtin 1 EC @ $0.003 \%$ were highly toxic to mealybug, Phenacoccus solenopsis Tinsley and its parasitoid, Aenasius bambawale $i$ Hayat in laboratory.

\section{References}

Badshah H., Farman Ullah, Calatayud, P. A., Hidayat Ullah and Bashir Ahmad 2017. Can toxicants used against cotton mealybug Phenacoccus solenopsis be compatible with an encyrtid parasitoid Aenasius bambawalei under laboratory conditions. Environmental Science and Pollution Research 24 (6): 5857-5867.

Badshah, H, Ullah F., Abid Farid and Calatayud P. A. N. 2015. Toxicity of Neem seed Azadirachta indica Juss (Meliaceae) different solvents extracts against cotton mealybug Phenacoccus solenopsis Tinsley (Sternorrhyncha: Pseudococcidae) under Laboratory conditions. Journal of Entomology and Zoology Studies, 3 (4): 45-49.

Bhatt, N. A., Jayani, D. B. and Patel, A. D. 2009. Mealy bug Phenacoccus solenopsis Tinsley an emerging pest of bidi tobacco in Gujarat. Symposium Abstracts. Proceedings of the National Symposium on IPM Strategies to Combat Emerging Pests in the Current Scenario of Climate Change held at CAU, Pasighet (Arunachal Pradesh) on January 38: 28-30.

Jhala, R.C., T. M. Bharpoda and M.G. Patel 2008. Phenacoccus solenopsis Tinsley (Hemiptera: Pseudococcidae), the mealybug species recorded first time on cotton and its alternate host plants in Gujarat, India. Uttar Pradesh J. Zool., 28: 403-406

Meenu and Pala Ram 2014. Effect of insecticides on different developmental stages of Aenasius bambawalei Hayat (Hymenoptera: Encyrtidae), a parasitoid of solenopsis mealybug, Phenacoccus solenopsis Tinsley, Journal of Biological Control, 28 (4): 204-209.

Nagrare, V. S., Kranthi, S., Kranthi, K. R., Naik, V. C. B., Vrushali Deshmukh, Bhausaheb Naikwadi and Ashish Dahekar 2016. Relative toxicity of insecticides against cotton mealybug Phenacoccus solenopsis Tinsley (Hemiptera: Pseudococcidae) and its fortuous parasitod Aenasius bambawalei Hayat (Hymenoptera: Encyrtidae). Journal of Applied and Natural Science 8 (2):987994

Nalini T. and Manickavasagam, S. 2011. Toxicity of selected insecticides to mealybug parasitoids, Aenasius bambawalei Hayat and Aenasius advena Compere (Hymenoptera: Encyrtidae). Journal of Biological Control, 25 (1): 14-17.

Sangle, P. M. Korat, D. M., Pawar, S. R. and Patel B. H. 2011. Relative toxicity of some insecticides to Aenasius bambawalei Hayat, an endoparasitoid of 
Phanococus solenopsis Tinsley. Insect Environment, 17 (3): 104-106.

Suroshe, S. S, Gautam, R. D. and Fand, B. B. 2014. Safety of insecticides against
Aenasius Bambawalei Hayat (Hymenoptera: Encyrtidae). Indian Journal of Entomology, 76 (3): 224228.

\section{How to cite this article:}

Bhatt, N.A. and Jalpa P. Lodaya. 2018. Evaluation of Insecticides against Tobacco Mealy Bug, Phenacoccus solenopsis Tinsley and its Parasitoid, Aenasius bambawalei Hayat under Laboratory Conditions. Int.J.Curr.Microbiol.App.Sci. 7(06): 2339-2343. doi: https://doi.org/10.20546/ijcmas.2018.706.279 